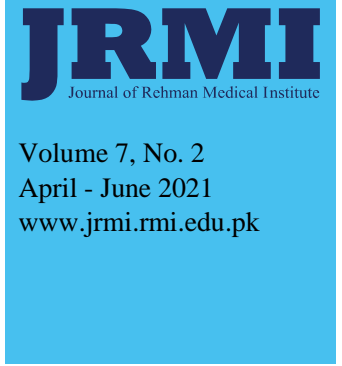

Submitted

March 18, 2021

Accepted

April 17, 2021

\section{Author Information}

From: Department of Surgery, Rehman Medical institute,

Peshawar, Khyber

Pakhtunkhwa, Pakistan

Professor Dr. Jamil Ahmad Consultant General Surgeon \& HOD

(Corresponding Author)

Email:

jamil.ahmad@rmi.edu.pk

Dr. Akash Kumar

House Officer

Professor Dr. Zubair Ahmad Khan

Consultant General Surgeon

Dr. Sarah Rahim

House Officer

Dr. Muhammad Mohsin

Medical Officer

Dr. Abbas Khan

House Officer

Citation: Ahmad J, Kumar A, Khan ZA, Rahim S, Mohsin

M, Khan A. Diabetic Foot: its grades and mode of

presentation at a tertiary care hospital of Peshawar, Khyber Pakhtunkhwa, Pakistan. J Rehman Med Inst. 2021 AprJun;7(2):3-6.

\title{
Diabetic Foot: its grades and mode of presentation at a tertiary care hospital of Peshawar, Khyber Pakhtunkhwa, Pakistan
}

Jamil Ahmad, Akash Kumar, Zubair Ahmad Khan, Sarah Rahim, Muhammad Mohsin, Abbas Khan

\section{ABSTRACT}

Introduction: Diabetic foot is defined as the foot of diabetic patients with ulceration, infection, and/or destruction of the deep tissues, associated with neurological abnormalities and various degrees of peripheral vascular disease in the lower limb. Foot ulcers are the principal cause of severe complications and hospitalization among patients with diabetes, substantially increasing the costs of this disease.

Objectives: To describe the presentation, distribute the diabetic foot lesions according to Wagner's classification, and determine the outcome of diabetic foot ulceration in a tertiary care hospital of Peshawar, Pakistan.

Materials \& Methods: This study was conducted in the Surgery department of Rehman Medical Institute Peshawar. Thirty nine (39) patients with diabetic foot disease presenting from Jan 2018 to Dec 2019 were included in the study. The patients were evaluated and managed by classifying their disease according to Wagner's classification for diabetic foot disease. Statistical analysis was done by using SPSS version 26 for descriptive statistics.

Results: The most common age of presentation with diabetic foot lesion was between 41-70 years; out of 39 patients, $28(71.8 \%)$ were males and $11(28.2 \%)$ were females. Their mode of presentation was as follows- 22 cases $(56.4 \%)$ with Ulcer, 9 cases $(23.1 \%)$ with Cellulitis, 7 cases (17.9\%) with Gangrene, and 1 case (2.6\%) with Abscess. The most common grade of presentation were grades 3 and 4 Wagner's lesion followed by Grade 1, and Grade 2. Debridement was the most common treatment modality (56.2\%), followed by Amputation (41\%).

Conclusion: Foot ulceration in diabetic patients is a resource-consuming, disabling morbidity that often is the first step towards lower extremity amputation. Diabetic foot lesions can be easily graded according to the Wagner classification and helps in correlating appropriate treatment to the grade of the lesion for a better outcome.

Keywords: Diabetes Mellitus; Diabetic Foot; Peripheral Vascular Diseases; Neuropathy.

The authors declared no conflict of interest. All authors contributed substantially to the planning of research, data collection, data analysis, and write-up of the article, and agreed to be accountable for all aspects of the work.

\section{INTRODUCTION}

According to the World Health Organization and the International Working Group on Diabetic Foot, diabetic foot is defined as the foot of diabetic patients with ulceration, infection, and/or destruction of the deep tissues, associated with neurological abnormalities and various degrees of peripheral vascular disease in the lower limb. ${ }^{1}$

Worldwide $10-25 \%$ of all diabetics develop some form of foot problems during their course of illness ranging from simple calluses to major abscesses out of which Foot Ulcers remain one of the most distressing complications of a diabetic patient. ${ }^{2,3}$

Foot Ulcers are the principal cause of severe complications and hospitalization among patients with diabetes, substantially increasing the costs of this disease. ${ }^{4}$ In the United States, the annual cost of foot ulcers is estimated at US $\$ 11$ billion. ${ }^{4,5}$

Outcomes of foot ulcers depend on the stage of the disease that patients present with. Common risk factors for amputation following ulceration include the presence of peripheral vascular disease, the severity of neuropathy, structural foot deformity, and concomitant infection. ${ }^{6-8}$

Lower Extremity Amputation (LEA) occurs 10-30 times more frequently in diabetic patients compared to non-diabetic patients and $70 \%$ of lower-limb amputations occur in people with diabetes, $85 \%$ of which follow foot ulceration. ${ }^{6,9,10}$

The prevalence of LEA, however, varies greatly across the world. ${ }^{11,12}$ In the USA a lower extremity amputation occurs at a rate of 8.6/1000 $(0.86 \%)$ diabetic subjects per year. However, in Pakistan despite a comparable prevalence of diabetic foot ulceration, the amputation rate was $21 \%$ but has also been reported to be as high as $48 \%$. $^{8,7,13}$

The purpose of this study was to define the presentation, to analyze and distribute the diabetic foot lesions according to Wagner's classification, as well as determining the outcome of diabetic foot ulceration in a tertiary care hospital of Peshawar Pakistan. 


\section{MATERIALS \& METHODS}

This study was conducted in the Department of Surgery at Rehman Medical Institute, Peshawar. Thirty-Nine (39) patients with diabetic foot disease presenting from Jan 2018 to Dec 2019 were included in the study.

Data were collected by taking a detailed history and clinical examination of the foot; its wound or ulcer was recorded. Data of patients with a chronic diabetic foot or previous amputation were collected from their previous records. Age, sex, socioeconomic status, duration of diabetes, Wagner's Classification, findings of clinical examination, investigations including blood glucose profile, renal functions, swabs from wound / ulcer, biopsy of the specimen, X-ray of the foot, and treatment carried out were recorded. The patients were evaluated and managed by classifying their disease according to Wagner's classification for diabetic foot disease (Table 1).

Table 1: Standard Treatment for Diabetic Foot according to Wagner's Classification

\begin{tabular}{|l|l|l|}
\hline \multicolumn{1}{|c|}{ Grades } & \multicolumn{1}{c|}{ Meggitt \& Wagner classification } & \multicolumn{1}{c|}{ Treatment } \\
\hline Grade-0 & Foot at Risk & Prevention \\
\hline Grade-1 & Localized, Superficial Ulcer & Antibiotics \& glycemic control \\
\hline Grade-2 & Deep Ulcer to the Tendon, Bone, Ligament, or Joint & Debridement, Antibiotics \& Glycemic control \\
\hline Grade-3 & Deep Abscess, Osteomyelitis & Debridement, some form of Amputation \\
\hline Grade-4 & Gangrene of Toes and Forefoot & Wide debridement and amputation \\
\hline Grade-5 & Gangrene of Entire Foot & Below knee amputation \\
\hline
\end{tabular}

Statistical analysis was done by using SPSS version 26. Descriptive analyses of age, sex, grade at presentation, and surgical procedure were performed.

\section{RESULTS}

The most common age of presentation with diabetic foot lesion was between $41-70$ years; $28(71.8 \%)$ patients were males and 11 (28.2\%) females. The mode of presentation was Ulcer (22 cases, $56.4 \%$ ), Cellulitis (09 cases, $23.1 \%$ ), Gangrene (07 cases, $17.9 \%$ ) and Abscess (01 case, 2.6\%). The most common site of presentation was Right foot in 16 patients $(41 \%)$ followed by Toe 09 (23.1), Left Foot 07 (17.9\%), Right leg 05 (12.8\%), and left leg $02(5.1 \%)$ as shown in Table 2.

Table 2: Demographic Profile of Patients $(n=39)$.

\begin{tabular}{|l|c|c|}
\hline \multicolumn{1}{|c|}{ Variables } & Frequency $(\mathbf{N})$ & Percent (\%) \\
\hline Age Group (years) & 02 & 05.1 \\
$20-30$ & 01 & 2.6 \\
$31-40$ & 09 & 23.1 \\
$41-50$ & 10 & 25.6 \\
$51-60$ & 12 & 30.8 \\
$61-70$ & 04 & 10.3 \\
$71-80$ & 01 & 02.6 \\
$81-90$ & & \\
\hline Gender & 28 & 71.8 \\
Male & 11 & 28.2 \\
Female & & \\
\hline Mode-of-Presentation & 07 & 17.9 \\
Gangrene & 22 & 56.4 \\
Ulcer & 09 & 23.1 \\
Cellulitis & 01 & 02.6 \\
Abscess & & \\
\hline Site-Of-Lesion & 09 & 23.1 \\
Toe & 16 & 41.0 \\
Right Foot & 07 & 17.9 \\
Left Foot & 05 & 12.8 \\
Right Leg & 02 & 05.1 \\
Left Leg & & \\
\hline
\end{tabular}

Grades of presentations based on Wagner's Classification of Diabetic foot are shown in Table 3. The most common grade of presentation according to Wagner's Classification were grades 3 and 4 Wagner's lesion followed by Grade 1, Grade 2. The ulcer was one of the most common presentations of Diabetic Foot (22 cases, $56.4 \%$ ).

Table 3: Grade of Presentation

\begin{tabular}{|c|c|c|}
\hline Grade & Number of Patients & Percent \\
\hline Grade 0 & 04 & 10.3 \\
\hline Grade 1 & 09 & 23.1 \\
\hline Grade 2 & 04 & 10.3 \\
\hline Grade 3 & 12 & 30.8 \\
\hline Grade 4 & 10 & 25.6 \\
\hline Grade 5 & 0 & 0 \\
\hline Total & $\mathbf{3 9}$ & $\mathbf{1 0 0 . 0}$ \\
\hline
\end{tabular}

Debridement was the most common treatment modality among various treatment modalities. In this study of 39 cases, 22 (56.4\%) patient required local debridement after initial surgery, and $16(41 \%)$ who were presented with diabetic foot and undergone amputation. Only one patient $(02.6 \%)$ had Incision and Drainage (Table 4).

Table 4: Treatment Provided $(n=39)$.

\begin{tabular}{|l|c|c|}
\hline \multicolumn{1}{|c|}{ Procedure } & Frequency & Percent \\
\hline Debridement & 22 & 56.2 \\
\hline Amputation & 16 & 41.0 \\
\hline Incision Drainage & 01 & 02.6 \\
\hline \multicolumn{1}{|c|}{ Total } & $\mathbf{3 9}$ & $\mathbf{1 0 0 . 0}$ \\
\hline
\end{tabular}

\section{DISCUSSION}

Diabetic foot is the most common complication in which diabetic patients suffer. ${ }^{14}$ It puts a huge burden on the health care system worldwide. Patients with diabetes are at risk of developing multiple complications making their feet vulnerable to damage. Foot infection and the subsequent amputation of a lower extremity are the most common cause of hospitalization among 
diabetic patients. Wagner's classification of the diabetic foot provided an objective grading and elucidation of standard treatment for diabetic foot disease.

Diabetic foot disease is more common in the older age group as compared to younger ones. In our study, the most commonly affected age group was 41-70 years with a mean age of 56.85 years. Similarly, a study was done in Rawalpindi, Islamabad And tertiary care hospitals of Peshawar and Abbottabad also suggested that the older age group (41-60 years) is more frequently affected with a mean age of 53.7 years. ${ }^{15,16}$

In this study, Diabetic foot disease was more common in males as compared to females with a percentage of $71.8 \%$. our results agreed with the previously published studies, Local and international that also showed a male predominance. ${ }^{17,18,13}$

Our results confirmed that most of the ulcers were in the forefoot (both right \& left) $59.0 \%$. Similar results were shown in a study by Aamir AH et al at Lady Reading Hospital, Peshawar ${ }^{7}$ and Lipsky BA et al in the USA. ${ }^{19}$

We use Wagner's classification system in our hospital setup for Diabetic foot Ulcer classification. In our study 4(10.3\%) patients with the foot at risk were in grade-0. Nine $(23.1 \%)$ patients with superficial ulceration and erythema, four $(10.3 \%)$ patients of deep ulceration with bad granulation tissue, twelve (30.8\%) patients had osteomyelitis while $10(25.6 \%)$ patients of gangrenous patches on pressure areas (toe and forefoot). In another local study, common presentations were patients with ulcers $21 \%$, and abscess in $31 \%$, and gangrene in $12.5 \% .^{16}$
Wagner's classification score may be different for a surgeon as compared to the physician because they come with advanced disease to a surgeon and for this reason patients with grades 3, 4 are more in our study.

The standard treatment for diabetic foot according to Wagner's classification is Prevention for grade-0, Antibiotics, and good glycemic control for grade-1. In grade-2 needs hospital admission, as they need surgical intervention along with antibiotics and glycemic control. Grade- 3 requires some sort of amputation, In grade- 4 wide debridement and amputation while in grade-5 the preferred treatment is below-knee amputation. In our $56.4 \%$ patients had debridement while $41 \%$ of patients needed amputations, like and another local study $33 \%$ of patients had debridement while $48 \%$ of patients needed amputations. ${ }^{16}$

\section{CONCLUSION}

Foot ulceration in diabetic patients is a resource-consuming, disabling morbidity that often is the first step towards lower extremity amputation. Prevention is the best treatment.

Grading diabetic foot lesions according to the Wagner classification was simple and easy. It helps in correlating appropriate treatment to the proper grade of the lesion with a better outcome. Plus effective diabetic control and patient education also play a vital role in decreasing diabetic foot disease. With early presentation and hospital admission, aggressive medical and surgical treatment according to the grade of the disease can improve outcome and reduce the morbidity and mortality due to diabetes.

\section{REFERENCES}

1. Mahakalkar CC, Kaple MN, Janardhan J, Jain N, Jaipuria P, Wagh DD. Pattern of diabetic foot - presentation and complications in rural Indian population. Int J Res Med Sci. 2015 Apr;3(4):948-53.

2. Ul-Muqim R, Griffin S, Ahmed M. Evaluation and management of diabetic foot according to Wagner's classification: a study of 100 cases. J Ayub Med Coll Abbottabad. 2003 JulSep;15(3):39-42.

3. Houghton AD, Taylor PR, Thurlow S, Rootes E, McColl I. Success rates for rehabilitation of vascular amputees: implications for preoperative assessment and amputation level. Br J Surg. 1992 Aug;79(8):753-5.

4. Quilici MTV, Fiol FDSD, Vieira AEF, Toledo MI. Risk factors for foot amputation in patients hospitalized for diabetic foot infection. J Diabetes Res. 2016;2016:8931508.

5. Gordois A, Scuffham P, Shearer A, Oglesby A, Tobian JA. The health care costs of diabetic peripheral neuropathy in the US. Diabetes Care. 2003 Jun;26(6):1790-5.
6. Millichap JG. Presentation and outcome of cranial aneurysms. Pediatr Neurol Briefs. 2006;20(3):17-8.

7. Aamir AH, Nasir A, Jadoon MZ, Mehmood K, Ali SS. Diabetic foot infections and their management in a tertiary care hospital. J Ayub Med Coll Abbottabad 2011Jan-Mar;23(1):58-62.

8. Ali SM, Basit A, Sheikh T, Mumtaz S, Hydrie MZ. Diabetic foot ulcer - a prospective study J Pak Med Assoc. 2001 Feb;51(2):78-81.

9. Singh N, Armstrong DG, Lipsky BA. Preventing foot ulcers in patients with diabetes. J Am Med Assoc. 2005;293:217-28.

10. Vileikyte L, Peyrot M, Bundy C, Rubin RR, Leventhal H, Mora P, et al. The development and validation of a neuropathy- and foot ulcer-specific quality of life instrument. Diabetes Care. 2003 Sep;26(9):2549-55.

11. O’Rourke I, Heard S, Treacy J, Gruen R, Whitbread C. Risks to feet in the top end: outcomes of diabetic foot complications. ANZ J Surg. 2002 Apr;72(4):282-6.
12. Reardon R, Simring D, Kim B, Mortensen J, Williams D, Leslie A. The diabetic foot ulcer. Aust J Gen Pract. 2020 May;49(5):250-5.

13. Jan WA, Shah HU, Usman M, Khan SM, Shah NA, Sharif N. Management of diabetic foot according to Wagner's classification and frequency of diabetic foot disease in other foot: a study of 98 cases. J Postgrad Med Inst. 2009 Aug 16;23(3):245-50.

14. Balk P, Colvin JR. Note on an indirect measurement of object temperatures in electron microscopy. KolloidZeitschrift.1961;176:141.

15. Shah FS, Hameed S, Khawaja Z, Abdullah T, Waqar SH, Zahid MA. Evaluation and Evaluation and management of diabetic foot: a multicenter study conducted at Rawalpindi, Islamabad. Ann Pak Inst Med Sci. 2011;7(4): 233-7.

16. Zafar A. Management of diabetic foottwo year experience. J Ayub Med Coll Abbottabad. 2001 Jan-Mar;13(1); 14-6. 
17. Blume PA, Walters J, Payne W, Ayala J, Lantis J. Comparison of negative pressure wound therapy usingVacuumassisted closure with advanced moist wound therapy in the treatment of diabetic foot ulcers. Diabetes Care. 2008 Apr;31(4):631-6.
18. Gul A, Basit A, Ali SM, Ahmadani MY, Miyan Z. Role of wound classification in predicting the outcome of Diabetic Foot Ulcer. J Pak Med Assoc. 2006 Oct;56(10):444-7.

19. Lipsky BA, Armstrong DG, Citron DM,
Tice AD, Morgenstern DE, Abramson MA. Ertapenem versus piperacillin / tazobactam for diabetic foot infections (SIDESTEP): prospective, randomised, controlled, double-blinded, multicentre trial. Lancet. 2005 Nov 12;366(9498):1695-703. 